\title{
Trabalhadores Rurais e Cidadania no Brasil - 1930-1964
}

Michelle Nunes de Morais*

Resumo: Este trabalho se originou nas discussões da disciplina "Brasil República: Cidadania e Poder" do curso de Mestrado em História da Universidade de Brasília. Tomamos para estudo a questão agrária e a exclusão dos trabalhadores rurais à cidadania, no período compreendido de 1930 até 1964 no Brasil. Buscamos compreender a questão agrária brasileira através do estudo da legislação e das constituições do país, assim como compreender a situação dos trabalhadores rurais na legislação trabalhista. Foi negado o status de cidadão aos trabalhadores rurais, ficando os mesmos marginalizados.

Palavras-chaves: cidadania; trabalhadores rurais; questão social.

Abstract: This work came from discussions in the seminar "Brazil Republic: Citizenship and Power" within the Master in History at the University of Brasilia. We have studied the land question and the exclusion of rural workers to citizenship, in the period from 1930 to 1964 in Brazil. We seek to understand the agrarian issue by studying the laws and constitutions of the country, as well as to understand the situation of rural workers in labor legislation. Was denied the status of citizen and rural workers were left marginalized.

Keywords: citizenship; rural workers; society question.

Apresentação

A cidadania no Brasil teve grande avanço a partir da década de 1930. Neste período a regulação do mercado de trabalho inseriu um número maior de pessoas no rol da cidadania através da CLT (Consolidação das Leis do Trabalho), implantada por Getúlio Vargas. Utilizamos principalmente neste trabalho o conceito de ausência de cidadania no Brasil até 1930, de José Murilo de Carvalho, e de Cidadania regulada, para o pós 1930, de Wanderley Guilherme dos Santos. Por conseguinte, estamos buscando analisar o lugar determinado aos trabalhadores rurais neste processo de evolução da cidadania no Brasil. Faremos uma análise da cidadania e da questão da terra durante o Império e Primeira República, mas nosso foco é do período compreendido de 1930 ao pré-1964. Nossa proposta é analisar a inserção dos trabalhadores rurais dentro do conceito de cidadania regulada. Acreditamos que se pode utilizar o conceito de não-cidadão de Carvalho para definir os trabalhadores rurais neste período.

Considerações acerca da cidadania

A “[...] cidadania é um produto social que exige tempo de maturação para aflorar e

\footnotetext{
* Mestranda em História Social no Programa de Pós-Graduação em História da Universidade de Brasília.
} 
desabrochar, enquanto processo, ela não é nem autônoma nem soberana, pois ao longo de seu percurso ela interage com outras entidades e processos sociais [...]" (HAGUETTE, 1994: 17 [grifos da autora]). Diante de tal exposto ela se

\begin{abstract}
materializa de forma sempre singular, a partir de determinantes históricos, políticos, econômicos e culturais. Não se pode falar dela sem se levar em consideração o Estado-nação em que se configura. No entanto, isso não é suficiente para que se compreenda como os indivíduos vivem, assimilam esse papel social e o representam. É preciso conhecer também a filosofia predominante, as crenças, as ideias políticas, os mitos, os ritos, as religiões, enfim, o imaginário social no qual se enraíza a cultura política de cada povo. Entenda-se por cultura política o conjunto de atividade pelas quais a comunidade institui o político, ou seja, o processo pelo qual a civitas se ordena e visa à realização de seus fins coletivos. É um conceito que engloba ações conscientes e inconscientes, intelectuais e emocionais, fundadas sempre em valores e significações. A partir disso é que a cidadania se institui. (FERREIRA, N., 1993: 185).
\end{abstract}

A cidadania se desenvolveu dentro do fenômeno dos Estados Nacionais e da Revolução Francesa (CARVALHO, 2008: 12). Ela se originou nas sociedades de classes e ao ser "conferida a um indivíduo, serve para identificá-lo na esfera pública” (FERREIRA, N., 1993: 19).

Cidadania no Brasil

Até 1822 a população da colônia se dividia entre os senhores, escravos e uma incipiente população, legalmente, livre e pobre, que não tinha, contudo, condições de exercer a cidadania. Durante o império isto não mudou muito. Segundo José Murilo de Carvalho (2008), nesse período o único movimento importante rumo à cidadania, mas que não teve implementação prática, foi a abolição da escravidão. A abolição não possibilitou a inserção dos ex-escravos no mercado de trabalho livre (CARVALHO, 2008: 17), sendo que a inserção dos mesmos à cidadania foi mais formal que prática. "A transição para o trabalho livre, longe de liberar a mão-de-obra de um rígido controle que lhe dá maior poder de barganha frente ao mercado, ao contrário, imobiliza-a nas zonas rurais decadentes [...]”' (GOMES, 2007: 156).

Em 1822, com a independência do Brasil, foram regulamentados os direitos políticos e em 1824 a Constituição Imperial definiu quem poderia votar e ser votado. Para os padrões da época, a Constituição do Império, era bastante liberal, pois permitia o voto para analfabeto. Era obrigatório o voto para os homens a partir dos 25 anos que comprovassem renda mínima de 100 Mil-réis, valor considerado baixo e que possibilitava a população pobre de votar. 
Ficaram excluídos do direito ao voto as mulheres e os escravos, mas os libertos, também, podiam votar, em eleições primárias. Em torno de $50 \%$ da população adulta masculina votavam, número bem acima dos países europeus (CARVALHO, 2008: 25-31).

Em 1881 houve um retrocesso na lei eleitoral. Foi implantado o voto direto e proibido o voto para analfabeto, assim como, o voto se tornou facultativo e a renda mínima aumentou para 200 Mil-réis. Para comprovar a renda foram adotadas regras mais rígidas o que dificultava sua comprovação. A grande maioria da população era analfabeta, o que fez com que o número de votantes nas eleições caísse drasticamente. Nas eleições de 1886 votaram apenas $0,8 \%$ da população, sendo que em 1872 votaram $13 \%$ da população, correspondendo a 50\% da população masculina (CARVALHO, 2008: 38-39).

Com a proclamação da república (1889), na nova constituição promulgada em 1891, continuou a proibição do voto aos analfabetos, mendigos, soldados, membros de ordens religiosas e, embora não houvesse proibição explícita, as mulheres que entraram com pedido para se alistarem para votar tiveram o mesmo negado (CARVALHO, 2008: 39 e KARAWEJCZYK, 2010: 4). Caracteriza-se esse período a exclusão e restrição de direitos, sendo que grande segmento da população ainda se manteve excluso do exercício dos direitos políticos e civis (NEVES, 1997: 93). Os direitos políticos continuaram restritos, os direitos civis era privilégio das classes abastadas e dos direitos sociais não se falava (NEVES, 1997: 94).

No que concerne os direitos sociais, um avanço importante durante a primeira república foi à entrada de imigrantes no país e o desenvolvimento do operariado urbano. Se não foi possível um desenvolvimento de cidadãos plenos, estes segmentos tiveram importante papel na luta por direitos civis e sociais (CARVALHO, 2008: 57-61 e NEVES, 1997: 94).

\footnotetext{
O movimento [operário] lutava por direitos básicos, como o de organizar-se, manifestar-se, de escolher o trabalho, de fazer greve. [...] Lutaram também por uma legislação trabalhista que regulasse o horário de trabalho, o descanso semanal, as férias, e por direitos sociais como o seguro de acidentes de trabalho e aposentadoria. (CARVALHO, 2008: 60).
}

"A constituição republicana proibia o governo federal interferir na regulamentação do trabalho" (CARVALHO, 2008: 61). Houve um retrocesso, durante a primeira república no que concerne aos direitos sociais, pois a constituição republicana suprimiu ao Estado o dever de fornecer educação primária, o que era obrigatório na constituição de 1824. A assistência social mantinha-se a partir de irmandades e associações, pois não havia legislação de amparo ao trabalhador (CARVALHO, 2008: 61). 
Somente em 1926 é que foi permitido ao Governo Federal legislar sobre o trabalho, com a primeira reforma constitucional. Antes deste período algumas leis foram sancionadas, mas não tiveram efeito prático, porém, mostra que havia um movimento em favor das leis trabalhistas. Em 1903 foi reconhecido o direito de organização sindical dos trabalhadores rurais e em 1907 dos trabalhadores urbanos, muito embora, houvesse uma dura repressão às estas organizações, o reconhecimento representou algum avanço em busca de conciliação entre patrões e empregados. Em 1919 foi estabelecida, aos patrões, a responsabilidade por acidentes de trabalho e em 1926 foi regulamentada a férias trabalhistas, entre outras medidas que, mesmo não sendo eficazmente implantadas, foram um avanço rumo à consolidação dos direitos civis e sociais (CARVALHO, 2008, p. 62-64 e SOUZA, 1997: 65-67).

Parafraseando Carvalho (2008), até 1930 não havia no Brasil cidadãos plenos, pois cidadão pleno é aquele que detêm os direitos políticos, civis e sociais. Aqueles que detêm apenas algum dos três direitos são cidadãos incompletos e os que não detêm nenhum dos direitos são não-cidadãos (CARVALHO, 2008: 9). Até a revolução de trinta havia uma ausência de cidadania no Brasil, devido à falta, ou precariedade na aplicação, de direitos (CARVALHO, 2008:18 e NEVES, 1997: 92). "Os direitos políticos beneficiavam a poucos, os direitos civis a pouquíssimos, dos direitos sociais ainda não se falava" (CARVALHO, 2008: 23).

O Governo Revolucionário (1930-1934) criou o Ministério do Trabalho, Indústria e Comércio e promulgou uma "vasta legislação trabalhista e previdenciária" que culminou na Consolidação das Leis do Trabalho (CLT) de 1943. Por conseguinte os direitos civis e políticos foram restringidos em nome do projeto modernizador do estado (CARVALHO, 2008: 87 e NEVES, 1997: 97).

Wanderley Cardoso dos Santos (1997) sugere, para definir a cidadania no Brasil pós década de 1930, o conceito de cidadania regulada. Os trabalhadores que tiveram suas profissões reconhecidas pela legislação foram inseridos no rol de cidadãos, enquanto aqueles que não tiveram suas profissões reconhecidas continuaram como pré-cidadãos. Segundo o autor

são cidadãos todos aqueles membros da comunidade que se encontram localizados em qualquer uma das ocupações reconhecidas e definidas em lei. [...] A cidadania esta embutida na profissão e os direitos do cidadão restringem-se aos direitos do lugar que ocupa no processo produtivo, tal como reconhecido por lei. Tornam-se pré-cidadão, assim todos aqueles, cuja ocupação a lei desconhece. (SANTOS, 1997: $68)$. 
A cidadania regulada, no entanto, não abrangeu todas as profissões (SANTOS, 1979 apud NEVES, 1997: 96), amplas camadas da população continuaram fora da mesma. Em 1932 foi implantada a Carteira de Trabalho e em 1933 foi criado o primeiro Instituto de Aposentadorias e Pensões. A cidadania regulada abrangeu somente os trabalhadores sindicalizados. Em 1931 promulgou-se a nova lei de sindicalização (Decreto no 19.770 - de 19 de março de 1931) regulamentando a sindicalização das classes patronais e operárias e em $1^{\circ}$ de maio de 1943, foi sancionado pelo Decreto-Lei $n^{\circ} 5.452$ a Consolidação das Leis do Trabalho, que em seu parágrafo $1^{\circ}$ estatuía "as normas que regulam as relações individuais e coletivas de trabalho". Já os Decretos-Leis de no 22.132 de 1932 e 23.768 de 1934 versava que somente os trabalhadores sindicalizados poderiam representar reclamações trabalhistas e gozar de férias. Os trabalhadores das profissões que não foram reguladas pela nova lei de sindicalização, ou seja, não foram reconhecidas pela mesma, continuaram fora da cidadania, como não-cidadão (SANTOS, 1997: 69).

A questão da terra

Durante a Colônia as terras brasileiras pertenciam à coroa portuguesa. A concessão de terras aos donatários das capitanias hereditárias era um direito político. “Os donatários recebiam apenas poderes políticos, como governantes mesmos, para exercê-los, em nome da Coroa, em circunscrição territorial delimitada na carta." Na própria carta era destinada uma porção de terra ao donatário, na qual ele "exercia não só sua autoridade política, como também direito de propriedade" (CUNHA JUNIOR). Em 1548 se extinguiu as capitanias Hereditárias e implantou-se o Governo-geral.

A Coroa portuguesa emitiu para os exploradores colonialistas os títulos de sesmarias que lhes davam apenas, o direito de uso das terras reais. Inclusive, caso não as explorassem, a Coroa podia retomá-las, como estava expresso no texto da Lei de 26 de Junho de 1375, que obrigava a prática da lavoura e o semeio da terra pelos proprietários arrendatários, foreiros, etc. (FARIA, 2009: 3 e CUNHA JUNIOR).

O regime sesmarial garantia a legitimidade da ocupação racional do território colonial, pois, durante a colônia não havia posse capitalista da terra. Por conseguinte, diferindo de Portugal, onde a concessão de sesmaria possibilitou a pequena propriedade, na colônia ele fez surgir o latifúndio (CUNHA JUNIOR). Outro fator que, também, consideramos importante para a acumulação da terra foi o regime de morgadio, extinto em 1835 (lei 57, de 06 de 
outubro). "Impedindo a subdivisão da terra, o morgadio tornava-se um obstáculo intransponível para a penetração do capital produtivo na agricultura" (PEREIRA \& PEREIRA, 2006).

\begin{abstract}
Num país em que a forma legítima de exploração do trabalho era a escravidão, e escravidão negra, os "bastardos", os que não tinham sangue limpo, os mestiços de brancos e índias, estavam destituídos do direito de herança, ao mesmo tempo em que excluídos da economia escravista. Foram esses os primeiros posseiros: eram obrigados a ocupar novos territórios porque não tinham lugar seguro e permanente nos territórios velhos. Eram os marginalizados da ordem escravista que, quando alcançados pelas fazendas e sesmarias dos brancos, transformavam-se em agregados para manter a sua posse enquanto conviesse ao fazendeiro, ou então iam para frente, abrir uma posse nova. (MARTINS, 1980: 70).
\end{abstract}

Em 1822 foi suspensa a concessão de sesmaria pela Resolução $N^{\circ} 76$ do Reino. Com o fim da concessão de sesmaria ficou um vago jurídico, até 1850, quando foi promulgada a lei da terra, sobre a aquisição e posse de terra, o que possibilitou aos renegados do direito a aquisição de terra, pelo regime de sesmaria, adquiri-las pela posse, mas também possibilitou o grilo de terras públicas e de todos os tipos de artimanhas para a sua aquisição (FARIA, 2009:4; CUNHA JUNIOR e MENEZES, 2008: 52).

A lei 601, de 18 de setembro de 1850, conhecida como Lei da Terra, segundo Cunha Junior "representou um marco na nossa legislação agrária".

\begin{abstract}
Os pontos básicos da Lei 601 foram: a proibição de doações de terras devolutas, exceto as situadas nas zonas de dez léguas limítrofes com países estrangeiros; a conceituação de terras devolutas, conceito este que até hoje serve de base para as legislações estaduais; a revalidação das sesmarias ou outras concessões do Governo Geral ou Provincial, que se achassem cultivadas ou com princípios de cultura e morada habitual do sesmeiro ou concessionário ou algum representante; a legitimação das posses mansas e pacíficas, adquiridas por ocupação primária, ou havidas do primeiro ocupante, que se achassem cultivadas ou com princípio de cultura, e morada habitual do posseiro ou representante; o usucapião nas sesmarias ou outras concessões do Governo; a discriminação das terras devolutas; a reserva de terras devolutas; o registro paroquial; as formas de venda de terras devolutas, etc.. (CUNHA JUNIOR).
\end{abstract}

A Lei da Terra veio para cobrir o vago jurídico da Resolução 76 de 1822, porém com ela surgiu alguns novos problemas quanto ao que concerne a legitimação de terras. Na lei versava a legalização de "títulos de sesmarias e as posses quaisquer que fossem suas extensões, mas que tivessem cultivos, desde que medidas e levadas a registro em livros próprios nas freguesias" (FARIA, 2009: 4), ocupadas antes de 1850. A lei determinava o prazo de dois anos para o registro e medição das posses nas freguesias no Livro paroquial, prazo que 
foi prorrogado várias vezes (FARIA, 2009: 5). Por conseguinte, havia preferência na legalização da titularidade da terra aquele que tinha o registro no livro Paroquial em detrimento do ocupante que trabalhava a terra (MENEZES, 2008: 52). Para o registro no livro paroquial era necessário à declaração do ocupante, ou por outra pessoa sendo este analfabeto, o que abriu margem para burlar as informações, todavia a declaração no registro paroquial "não conferiam direito aos possuidores" (SILVA L., 1996: 173).

O título da terra tornou-se pela lei superior à posse efetiva. Assim, aquele que tinha efetivamente a posse da terra estava destituído do direito sobre ela. E garantiu, portanto, a aquele que sendo portador do título da terra, mesmo, sem nunca tê-la ocupado de fato, ter o domínio sobre a mesma, ou seja, o direito de propriedade privada da terra. (FARIA, 2009: 5).

A aquisição de terras, a partir de então, somente seria pela compra, "transformando, assim, os ocupantes de terras devolutas transgressores da lei” (FARIA, 2009: 7). Esta medida "praticamente sentencia a que só quem tem condições de pagar pode adquirir terra, o que excluía o escravo liberto, o imigrante que vem trabalhar nas fazendas, as pessoas pobres em geral” (MENEZES, 2008: 51).

Esta legislação teve pouco avanço no que se refere à regulação fundiária. As ocupações irregulares continuaram e o governo imperial tomou novas medidas para tentar remediar a situação. Em 1873 o governo divulgou que permitiria os que ocuparam irregularmente terras devolutas, a partir de 1854, a compra das mesmas. Entretanto, em alguns casos, os que ocuparam terras devolutas a partir de 1854 as registravam no Livro Paroquial com data retroativa a 1850 (SILVA L, 1996: 205). "Assim, o Brasil chegou à República um ano depois do final da escravidão, proclamada pelos militares sem uma definição real da constituição da propriedade privada, assim como sobre as terras devolutas." (FARIA, 2009: $8)$.

A lei da terra continuou em vigor após a proclamação da república. Para tentar organizar a questão do registro de terras, em 1890 foi instituído o registro Torrens, que visava disciplinar a propriedade dos imóveis rurais. Todavia, ele não conseguiu regularizar a situação fundiária no país (FARIA, 2009:11 e MENEZES, 2008:53).

Em 24 de fevereiro de 1891 foi promulgada a primeira Constituição republicana e todas as terras devolutas passaram para os Estados. Segundo o texto da Constituição à União somente caberia "a porção do território que for indispensável para a defesa das fronteiras, fortificações, construções militares e estradas de ferro federais" (CONSTITUIÇÃO 
FEDERAL, 1891, art. 64). Os Estados deveriam elaborar as constituições e leis próprias para legitimação de terras, enquanto não o fizessem continuaria vigente a lei da terra de 1850 .

Segundo Ligia Osório e Silva (1996, p. 252)

todos os estados alteraram a data de validade das posses, para efeito de legitimação. A lei de 1850, como sabemos, havia estabelecido 1854 (ano da sua regulamentação) como limite para os processos de legitimação. Isso significava que as posses ocorridas após 1854 não podiam ser legitimadas dentro dos benefícios da lei. $\mathrm{O}$ máximo que uma legislação especial ainda no Império permitia era que os posseiros tivessem prioridade na compra das suas posses. Ao adotarem suas leis de terras, todos os estados alteraram essa data para, pelo menos, 1889. Em casos significativos para muito mais tarde, por exemplo, 1920 [...] Ao mesmo tempo, dilataram os prazos para os pedidos de legitimação até o final da Primeira República (1930).

No estado de Minas Gerais somente em 1949 "é que procurou estabelecer normas mais explicitas para a regulamentação das transações de terras devolutas entre o Estado e Particulares” (BORGES, 1991: 185), através da Lei nº 550 de 05 de junho de 1949.

O processo de ocupação irregular de terras devolutas continuou em todo território nacional, assim como a legitimação de posses pelos chefes dos governos estaduais, baseadas na lei da terra de 1850, até 1931 (SILVA L., 1996: 252-253). O código civil de 1916 regulamentou a transmissão da propriedade da terra pela compra e venda, mas mesmo assim, continuou imperando no Brasil o conceito de usucapião das terras públicas até o

\begin{abstract}
Governo Provisório assinar, em 1931, o Decreto n. 19.924 que dispunha especificamente sobre as terras devolutas e que colocou um ponto final nesta questão, reconhecendo às concessões de terras processadas pelo regime anterior, porém, consagrou dali em diante a necessidade da transcrição como ato indispensável para a validade dos títulos de terras. O Governo Provisório de Vargas publicou também, dois anos depois, em 1933, o Decreto n. 22.785, cujo objetivo era vedar o resgate dos aforamentos de terrenos pertencentes ao domínio da União que instituíam a proibição do usucapião sobre bens públicos. (FARIA, 2009, p. 13).
\end{abstract}

Já a Constituição Federal de 16 de julho de 1934 versava em seu artigo 125 que

todo brasileiro que, não sendo proprietário rural ou urbano, ocupar, por dez anos contínuos, sem oposição nem reconhecimento de domínio alheio, um trecho de terra até dez hectares, tornando-o produtivo por seu trabalho e tendo nele a sua morada, adquirirá o domínio do solo, mediante sentença declaratória devidamente transcrita.

Na Constituição de 1937 o artigo 148, manteve na integra o texto do artigo 125 da Constituição de 1934. Getúlio Vargas também buscou incentivar a constituição de pequenos 
proprietários de terras, através de colônias agrícolas. No artigo $1^{\circ}$ do Decreto-Lei 2.009 , de 09 de fevereiro de 1940 versava que a União, Estados, Municípios, empresas de viação férrea ou fluvial, companhias, associações e particulares, poderiam promover núcleos de colonização, formados por pequenas propriedades rurais. Assim como, o Decreto-Lei 3.059, de 14 de fevereiro de 1941 versava que a União, em consonância com os Estados e Municípios, iria promover a criação de grandes colônias agrícolas, por intermédio do Ministério da Agricultura.

A Constituição de 1946 buscou solucionar a questão da ocupação irregular que, ainda, imperava no país e a acumulação agrária, sendo assim ela traz:

\footnotetext{
Art. 156 - A lei facilitará a fixação do homem no campo, estabelecendo planos de colonização e de aproveitamento das terras pública. Para esse fim, serão preferidos os nacionais e, dentre eles, os habitantes das zonas empobrecidas e os desempregados.

$\S 1^{\circ}$ - Os Estados assegurarão aos posseiros de terras devolutas, que nelas tenham morada habitual, preferência para aquisição até vinte e cinco hectares.

$\S 2^{\circ}$ - Sem prévia autorização do Senado Federal, não se fará qualquer alienação ou concessão de terras públicas com área superior a dez mil hectares.

$\S 3^{\circ}$ - Todo aquele que, não sendo proprietário rural nem urbano, ocupar, por dez anos ininterruptos, sem oposição nem reconhecimento de domínio alheio, trecho de terra não superior a vinte e cinco hectares, tornando-o produtivo por seu trabalho e tendo nele sua morada, adquirir-lhe-á a propriedade, mediante sentença declaratória devidamente transcrita.
}

Apesar de toda legislação, até 1964, quando da promulgação da Lei no 4.504, de 30 de novembro de 1964 - Estatuto da Terra, a ocupação irregular ainda vigorava em todo o país. O Estatuto da Terra pretendia modificar a posse e uso da terra através da melhor distribuição da mesma (BRUNO, 1995). Embora sem implantação prática, somente a partir do Estatuto da Terra é que a Lei da Terra, de 1850, foi definitivamente suprimida.

Os conflitos agrários e as políticas públicas

Para Leonildes Sérvolo de Medeiros (1989 e 2010) os conflitos de terra no Brasil iniciam com as fugas dos escravos, posteriormente teremos conflitos entre imigrantes e fazendeiros no interior de São Paulo, os movimentos messiânicos, entre outros. Segundo a autora, sempre houve uma tentativa de desqualificação dos mesmos, e eles somente entraram na pauta de mobilizações sociais a partir de 1945. 
Os conflitos de terra eram localizados e regionais (MEDEIROS, 2010: 114), não representavam repercussão nacional, sendo caracterizados como caso de polícia (BORGES M., 1991: 179) e não de políticas públicas. Isso fez com que conquistas tidas por trabalhadores urbanos não chegassem ao campo. Esta realidade passa por uma reformulação a partir da “intensificação do processo de industrialização, redefinição do papel da agricultura na economia, constituição de um projeto desenvolvimentista etc., as lutas dos trabalhadores rurais provocaram a emergência de novos sujeitos” (MEDEIROS, 1989: 14).

A partir de 1940 a questão agrária ganhou repercussão nacional. Antes, já vinham sendo tomadas algumas ações visando amenizar os conflitos nas áreas rurais, que, entretanto, não foram efetivamente implementadas. Em 1903 foram reconhecidos os sindicatos rurais, pelo Decreto-Lei 979 de 06 de janeiro de 1903, que no seu Art. $1^{\circ}$ dizia que "é facultado aos profissionais da agricultura e indústrias ruraes de qualquer gênero organizarem entre si syndicatos para o estudo, custeio e defesa dos seus interesses" (texto original). Segundo Carvalho (2008) esta lei foi motivada por pressão das representações diplomáticas dos países dos trabalhadores imigrantes que vinham para o país trabalharem nas lavouras de café, todavia o texto não definia as categorias de trabalhadores. No entanto, de 1893 até 1927, foram promulgadas diversas leis de repressão à atividade sindical por parte dos trabalhadores, "todas visando, sobretudo, à expulsão de trabalhadores estrangeiros por motivos de militância sindical" (SANTOS, 1997: 65).

O Decreto 979, de 1903 foi revogado pelo Decreto $\mathrm{n}^{\circ} 23.611$, de 20 de dezembro de 1933, que também facultava a instituição de consórcios profissionais-cooperativos

\footnotetext{
Considerando que ha necessidade de regularizar a situação dos sindicatos fundados de acôrdo com o decreto legislativo n. 979, de 6 de janeiro de 1903, para que êles possam se amoldar à, nova forma e entrar no goso dos favores e das faculdades por êste concedidos aos consórcios profissionais - cooperativos. (DECRETO n ${ }^{\circ} 23.611$, de 20 de dezembro de 1933[texto original]).
}

Nesta lei foram definidas as categorias profissionais que poderiam se associarem. No art. $2^{\mathrm{a}}$, define os "agrários - o proprietário, o cultivador, o arrendatário, o parceiro, o colôno, o criador de gado, o jornaleiro e quaisquer pessoas empregadas em serviços rurais;" (DECRETO $n^{\circ}$ 23.611, art. $2^{\text {a }}$, I. de 20 de dezembro de 1933) observa-se que não foram diferenciados os empregados e empregadores, assim como diversos segmentos dos trabalhadores rurais não foram contemplados, pois quaisquer pessoas empregadas em serviços rurais deixou vago o texto da lei. A lei, por não diferenciar os trabalhadores rurais dos proprietários rurais, abriu brecha para que se criassem associações mistas. 
A Constituição de 1934 versava em seu Art. 121 - “A lei promoverá o amparo da produção e estabelecerá as condições do trabalho, na cidade e nos campos, tendo em vista a proteção social do trabalhador e os interesses econômicos do País.” Por isso,

\begin{abstract}
em 1937 foi apresentada à Câmara de Deputados um projeto de Código Rural, voltado para a regulação de direitos e obrigações relacionadas às atividades rurais. Nele procurava-se definir o que era empregado rural e regulamentar tanto o sistema de barracões de engenho, como as relações de trabalho nos seringais. Embora não tenha chegado a finalizar a discussão desse projeto, o tema da tradução das categorias existentes no campo para termos legais manteve-se na pauta política, por meio do debate em torno da regulamentação do direito de associação. Ao contrário da legislação Fabril, que previa o direito de associação sindical a trabalhadores e empregadores, constituindo estruturas paralelas, o Ministério da Agricultura e os empresários rurais pregavam uma organização mista para o campo. (MEDEIROS, 2010, p. 115).
\end{abstract}

Em 10 novembro de 1944 foi assinado o Decreto-Lei $n^{\circ} 7.038$ que "garantia a representação paralela para patrões e empregados. Nele eram definidos como empregados os que trabalhassem por conta de outrem. Caberia ao Ministério do Trabalho o reconhecimento das entidades de representação" (MEDEIROS, 2010: 116). O $\operatorname{artigo} 2^{\circ}$ definia "são empregados rurais, trabalhadores ou operários rurais aqueles que se dedicam profissionalmente às atividades rurais, em economia individual, coletiva ou de família, na lavoura, na pecuária ou nas indústrias rurais, cem o fito de ganho e por conta de outrem (sic)" (DECRETO-Lei $\mathrm{n}^{\circ}$ 7.038, 10 de novembro de 1944, art. $2^{\circ}$ [texto original]).

Em abril de 1945 foi editado o Decreto-Lei $n^{0} 7.449$ "que definia a formação de associações rurais como organizações mistas" (MEDEIROS, 2010: 116) que não seria submetido a enquadramento profissional, mas a jurisdição territorial do município. Meses depois foi sancionado o Decreto-Lei no 8.127 de 24 de outubro de 1945, dando nova redação ao Decreto-Lei 7.449/45. Nestas leis não foram garantidos, aos trabalhadores rurais, os direitos trabalhistas do operariado urbano, elas somente versavam sobre a organização da vida rural.

A extensão destas medidas não foi ampla, pois durante o governo Vargas somente seis sindicatos de Trabalhadores Rurais foram reconhecidos, pelo Ministério do Trabalho, sendo em sua maioria ligados as Usinas de Produção de Açúcar, ou seja, operários rurais (GOMES, 2007: 171; SILVA M., 2006: 11 e WELCH, 2009: 1).

Muitas eram as dificuldades para esse tipo de organização: a legislação trabalhista era feita para os trabalhadores urbanos, não considerando a especificidade do trabalho do campo, quase não existiam juntas de conciliação e julgamento nas 
cidades do interior, o código civil não permitia a organização de sindicatos rurais, os proprietários rurais agiam de forma repressiva, inclusive acionando a polícia para reprimir qualquer tentativa de organização e mobilização dos trabalhadores (as) rurais. (SILVA M., 2006: 11).

A questão da cidadania no Brasil e os trabalhadores rurais

A cidadania é fruto da sociedade classes, por conseguinte ela nasce com o modo de produção capitalista. No entanto, no Brasil o modelo de produção capitalista desenvolveu-se tardiamente e em concomitância com o modelo de concentração fundiária.

Somente a partir de década de 1930 é que houve avanços no que concerne a cidadania no Brasil (CARVALHO, 2008, 54). O Estado Novo trouxe para a discussão os direitos sociais, propondo leis trabalhistas para atender os trabalhadores urbanos. Por conseguinte, os trabalhadores rurais continuaram excluídos da legislação trabalhista até a década 1970, quando foi criado, pelo regime militar, o FUNRURAL, que inseriu os trabalhadores rurais na cidadania regulada (MEDEIROS, 2010).

A não inserção dos trabalhadores rurais no projeto de cidadania,

[...] na verdade, era parte do pacto sócio-político que prevaleceu no Brasil por muito tempo. $\mathrm{O}$ arranco industrial inicial no Brasil não encontrou a agricultura como um empecilho a seu desenvolvimento razão porque não the foi dada prioridade em termos de alocação de fundos. (HAGUETTE, 1994, p. 122).

Tomando como referência a cidadania regulada (SANTOS, 1997), consideramos que os trabalhadores rurais estavam inseridos no rol dos pré-cidadãos. Sendo assim, temos uma sociedade de desiguais, que favorece o surgimento de estratificações sociais e a sobreposição de classes antagônicas de cidadãos e não cidadãos, que podem ser definidos como marginais sociais (FERREIRA, N., 1993: 160-161).

"A marginalidade assim como a cidadania, resulta das sociedades de classes, é um fenômeno que revela as relações perversas do modo de produção capitalista, cuja racionalidade funciona com base no binômio inclusão/exclusão" (FERREIRA, N., 1993: 161). Os trabalhadores rurais continuaram marginalizados, ou seja, fora das relações, de trabalho, regulada pela legislação trabalhista.

Por motivos específicos do tipo de desenvolvimento do capitalismo no Brasil, a área rural emergiu da escravidão para uma forma de organização econômica e social que se estruturava pela interpenetração de um mercantilismo parcialmente de jure e um sistema de servidão de fato. E, assim, atravessou a força de trabalho agrícola os 
períodos do laissez-fairianismo repressivo e da extensão regulada da cidadania sem que sua identidade social fosse definida quer pelo mercado, quer administrativamente. (SANTOS, 1997: 83).

Getúlio Vargas, visando incentivar o desenvolvimento industrial e de avançar a fronteira de expansão do capitalismo agrário para o interior, encampou a Marcha para o Oeste (BORGES, B., 1996: 37-55 e MEDEIROS, 2002: 7), isso levou a uma sobreposição de interesses das populações, geralmente posseiros, que ocupavam as terras das fronteiras, a revelia do estado, e a nova frente de expansão do capitalismo agrário. A abertura de estradas, implantação de usinas siderúrgicas e os projetos de colônias agrárias (entre outras medidas) produziram ou agravaram os confrontos nas áreas rurais (GOMES, 2007: 170-171).

\begin{abstract}
[A] Marcha para o Oeste, entendida como um movimento necessário e complementar ao amparo que o governo dera ao operário industrial: tratava-se de levar orientação técnica e instrumental agrícola para o interior, abertura de estradas, reformulação do ensino agrícola, etc, medidas entendidas como fundamentais para a melhoria das condições de vida dos trabalhadores rurais, proporcionando incentivo ao comércio e a fixação à terra. Para incentivar a permanência dos trabalhadores no campo, fez-se inclusive a concessão de passagens, para que os descontentes com a cidade pudessem voltar ao meio rural. Ao mesmo tempo, o Departamento de Imigração encaminhava anualmente centenas trabalhadores rurais para diversos pontos do país. (MEDEIROS, 2002, p. 7).
\end{abstract}

No Vale do Rio Doce o que acirrou os ânimos foi à construção da BR-Rio/Bahia, a partir da década 1930, a implantação das Usinas Siderúrgicas, na região do Leste de Minas (Quadrilátero Ferrífero) e a exploração de mica (mineral utilizado na indústria bélica), na década de 1940. A valorização das terras da região fez com que para lá se dirigissem "grileiros de todas as regiões, madeireiros, empresas estrangeiras voltadas para a extração da Mica e do Berilo, empresas siderúrgicas [...]" (BORGES, M., 199: 177), motivados pela construção da Rio-Bahia, que teve início em 1934, que possibilitou a introdução da pecuária de invernada, que embora de fundamental importância para o desenvolvimento econômico da região, também, foi o que agravou a expropriação das terras para a criação de gado (ESPINDOLA, 1998).

Carlo Castaldi (2008) vê na construção da Rio-Bahia o fator das expropriações de terra nos Sertões do Vale do Rio Doce. O autor diz que a BR levou interesses diversos para a região, pois com a chegada da estrada houve uma valorização das terras e para lá se dirigiram especuladores com a intenção de legalização da terra, não com o fim de produzir, mas, de garantir a venda (CASTALDI, 2008: 343-344). 


\title{
A fronteira
}

“O campo brasileiro continuou a se desenvolver a partir de uma noção ambígua de fronteira na qual esta era, inicialmente, ocupada por posseiros sem direitos de propriedade para, em seguida, ser ocupada por grandes proprietários com títulos de terra de origem duvidosa" (AVRITZIR, 2007: 157). As terras passam das mãos dos posseiros, para as mãos dos latifundiários, aqueles em muitas situações não abrem mãos delas de bom grado, o que leva a conflitos e/ou resistência de diversos tipos: de surto místico (CASTALDI, 2008) a rebelião (BORGES, M., 1991: 2004). Leila de Menezes Stain (2008: 29), diz que

\begin{abstract}
esses conflitos são, basicamente, de dois tipos. Primeiro, aqueles que ocorrem a partir do rompimento entre relações de trabalho e meios de vida; o segundo, aqueles que ocorrem nas áreas de ocupação de terras novas nas fronteiras econômicas do país. No segundo caso, há um encontro entre frente pioneira - aquela cuja característica é uma atividade não-fundamentada na apropriação capitalista da terra e a frente de expansão, isto é, as atividades agrícolas fundadas na propriedade legalmente titulada da terra. Desse modo, a superposição das duas frentes ocasiona o surgimento de choques e conflitos.
\end{abstract}

A fronteira é o locus de conflito por excelência (FERREIRA, A., 2009). O Leste de Minas foi à nova fronteira agrícola do Estado de Minas Gerais a partir da abertura da Rodovia Rio-Bahia. Assim teremos a fronteira como bem ilimitado, e como foco de conflitos entre os pioneiros (posseiros) e a expansão do capitalismo agrário (latifundiários) (BORGES, M., 1991: 175 e 178).

Segundo Guillaume Boccara (2005) as áreas de fronteira são as regiões habitadas por populações sem uma organização política centralizada, sendo que estas zonas de fronteira são consideradas áreas não civilizadas.

\begin{abstract}
A fronteira pode primeiramente ser entendida como o resultado de um ato político que delimita linhas de divisão territorial. Mas a fronteira ainda tem outro sentido, sociológico, empregado como operador descritivo de realidades sociais nas quais a dimensão territorial ocupa um lugar central. A fronteira não é apenas uma linha demarcatória que divide um território e marca os limites da soberania de um Estado nacional, mas é também, e principalmente, o objeto de relações e dinâmicas sociais que definem e a redefinem continuamente. Devemos então, desde já, indicar que o conceito político-jurídico de fronteira expressa apenas uma dimensão ou um uso possível, aos quais podemos adicionar outros, como os de fronteira agrícola, extrativista, etc. (FERREIRA, A., 2009: 5).
\end{abstract}

A fronteira é vista como um objeto de transição, no qual o colonizador vê-se destinado a unir dois mundos antagônicos, o civilizado e o não civilizado. $\mathrm{O}$ que motiva a necessidade 
de resistir ao invasor (BOCCARA, 2005). Podemos dizer que aquele grupo da primeira entrada no Vale, conhecido como posseiro, a partir da segunda entrada na década de 1930, serão ressignificados e assimilados dentro do novo projeto de colonização do Vale do Rio Doce, baseados na visão do desenvolvimentista varguista, conhecido como Marcha para o Oeste.

$\mathrm{Na}$ fronteira aberta a ocupação da terra não acontece de forma uniforme e irreversível. A transformação da fronteira em frente de expansão (capitalista), "que é um objeto empírico envolvendo tipos de atividade, a combinação concreta de forças produtivas e relações de produção que se introduz em uma área de fronteira leva", ao fechamento da mesma, o que implica em "uma estruturação das relações espaciais e sociais, no estabelecimento de um padrão dominante de relação dos grupos sociais com os territórios e os espaços" (FERREIRA, A., 2009: 5).

No Brasil a ocupação das regiões de fronteira aconteceu mais "por um fenômeno de pura mobilidade" (Richard M. Morse apud VELHO, 1979: 114). Nestas regiões apareceu uma população marginal, que viviam da agricultura de subsistência (VELHO, 1979: 116-119). Já a ocupação da fronteira do Leste de Minas - Médio Rio Doce - ocorreu mediante uma ideologia da terra como bem ilimitado (BORGES, M., 2004: 95), que foi fomentada pela mentalidade de apropriação mercantilizada e especulativa da terra (CAMBRAIA, 1988: 148-149). O que, consequentemente, com a construção da Rodovia Rio-Bahia, dos Programas Rio Doce e Mica - implantados a partir da assinatura do Acordo de Washington - se agravaram (GENOVEZ, 2010: 119).

O desenvolvimentismo varguista e as populações rurais

Segundo Antônio Cândido (1975) o contato de populações de cultura tradicional, com novos valores culturais pode levar "ao esquistamento [sic], a desorganização ou a aculturação". Ele alega que "a passagem de um tipo de cultura a outro depende em grande parte [...] do ritmo com que se dá a incorporação dos traços" (CANDIDO, 1975: 200). Se a incorporação é lenta encontra resistência, mas se é rápido demais leva a "desorganização dos padrões anteriores, antes de haver possibilidade de integrar[-se] [sic] os novos" (idem: 200) padrões. O progresso rápido leva os grupos de cultura tradicional a uma crise de valores inerentes a sua forma de reprodução cultural, pois há uma imposição violenta de uma nova 
realidade cultural, no qual o grupo é obrigado a romper com seus valores culturais tradicionais, mas não lhes são dadas condições de se inserirem a nova cultura (idem: 219).

A industrialização do país a partir da década de 1930, motivado pelo desenvolvimentismo varguista, incentivou o avanço da fronteira agrícola para áreas ainda não colonizadas. Diversos órgãos privados e públicos financiaram a expansão das frentes de ocupação, tais como: “o capital comercial e bancário, através de empresas colonizadoras vinculadas a companhias de estradas de ferro, grupos econômicos nacionais e estrangeiros e entidades governamentais" (BORGES, B., 1996: 39-40).

Segundo Bolsanulfo G. Borges (1996) o estado estabeleceu tanto políticas de industrialização quanto de colonização, por isso implantou diversas colônias agrárias em todo o país, medida que tinha como fim incentivar a pequena propriedade. Por conseguinte, as áreas de fronteira inicialmente foram colonizadas por pequenos proprietários - posseiros que dedicavam a agricultura de subsistência, posteriormente, com a expansão da fronteira agrícola, para estas áreas migraram o capital agrário, que implantou uma forma de relação de propriedade privada da terra ainda desconhecida do posseiro. Isto agravou os conflitos entre posseiros, primeiros ocupantes destas terras, e os grandes proprietários, novos donos - legais - das mesmas (BORGES, B., 1996: 40-50).

No caso do Vale do Rio Doce, os posseiros no decorrer dos anos de 1930-1940, com a implantação da pecuária de invernada, serão transformados em assalariados rurais, parceiros, meeiros, etc. Posteriormente com os pastos já formados eles serão expulsos do campo indo integrar-se a mão-de-obra desempregada de Governador Valadares (BORGES, M., 1991: 179).

Até o inicio dos anos 1960, apesar das legislações, nenhuma ação foi efetivamente implementada visando conter os conflitos agrários. Somente com a portaria 355-A de 20 de Novembro 1962 é que foi regulamentada a Sindicalização Rural e efetivada uma grande campanha do estado para criação de Sindicatos de Trabalhadores Rurais via SUPRA (MEDEIROS, 1986: 63).

A promulgação do Estatuto do Trabalhador Rural, pela Lei $\mathrm{n}^{\circ} 4.214$, de 02 de março de 1964, foi uma tentativa, do Presidente João Goulart, de regulamentar "as relações do trabalho Rural". Ele estendeu aos trabalhadores rurais os direitos dos trabalhadores urbanos, como carteira de trabalho (art. 13), indenização por acidente de trabalho ou moléstia profissional (art. 13 alínea c), implantação do Fundo de Assistência e Previdência do Trabalhador Rural (art. $10 \S 2^{\circ}$ ) entre outras. Ele foi uma tentativa de incorporar os 
trabalhadores rurais na cidadania, mas, com o Golpe Civil/Militar de 1964 permaneceu "letra morta [...]. Os trabalhadores do campo continuaram excluídos" (CARVALHO, 2008: 153), ou seja, pré-cidadãos, não-cidadãos e/ou marginais sociais.

A Lei 4.214/1964 foi revogada, em 08 de junho de 1973, pela Lei no 5.889 que regulou o trabalho rural. Já em 25 de maio 1971 a lei complementar nº11 instituiu o Programa de Assistência ao Trabalhador Rural, executado pelo FUNRURAL. A lei no seu art. $1^{\mathbf{o}} \S 2^{\mathbf{o}}$ dizia "O FUNRURAL gozará em toda a sua plenitude, inclusive no que se refere a seus bens, serviços e ações, das regalias, privilégios e imunidades da União e terá por foro o da sua sede, na Capital da República, ou o da Capital do Estado para os atos do âmbito deste”. Somente com a criação do FUNRURAL é que os trabalhadores rurais puderam gozar do status de cidadão (SANTOS, 1997: 84-85).

\section{Referências Bibliográficas}

\section{Constituições:}

CONSTITUIÇÕES Política do Imperio do Brasil (de 25 de Março de 1824). Disponível em:<www.planalto.gov.br/ccivil_03/.../constituiçao24>. Acessado em 24 de julho de 2011, as 20:13 horas.

CONSTITUIÇÃO da República dos Estados Unidos do Brasil (24 de fevereiro de 1891). Disponível em:< www.planalto.gov.br/ccivil_03/.../constituiçao24>. Acessado em 24 de julho de 2011, as 20:14 horas.

CONSTITUIÇÃO da República dos Estados Unidos do Brasil (de 16 de julho de 1934). Disponível em:<www.planalto.gov.br/ccivil_03/.../constituiçao24>. Acessado em 24 de julho de 2011, as 20:15 horas.

CONSTITUIÇÃO dos Estados Unidos do Brasil (10 de novembro de 1937). Disponível em:<www.planalto.gov.br/ccivil_03/.../constituiçao24>. Acessado em 24 de julho de 2011, as 20:16 horas.

CONSTITUIÇÃO dos Estados Unidos do Brasil (de 18 de setembro de 1946). Disponível

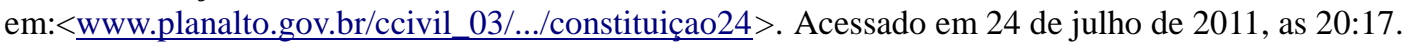

Legislação:

LEI $\mathrm{n}^{\circ}$ 601, de 18 de Setembro de 1850, dispões sobre as terras devolutas do Império. Disponível em:<www.planalto.gov.br/ccivil 03/Leis/L0601-1850>. Acessado em 24 de julho de 2011, as 20:18 horas.

DECRETO $\mathrm{n}^{\circ}$ 979, de 06 de janeiro de 1903, faculta aos profissionais da agricultura e industria ruraes e organização de syndicatos para defesa de seus interesses. Disponível em: $<$ www.jusbrasil.com.br/legislacao/103710/decreto-979-03. Acessado em 22 de julho de 2011 as 15:00.

DECRETO no 19.770, de 19 de março de 1931, regula a sindicalização das classes patronais e operárias. Disponível em:〈www2.camara.gov.br > Atividade Legislativa > Legislação $>$. Acessado em 24 de julho de 2011, as 22:21 horas.

DECRETO n 23.611, de 20 de dezembro de 1933, revoga o decreto nº79, de 06 de janeiro de 1903 e faculta a instituição de consórcios profissionais-cooperativos. Disponível 
em:<www.jusbrasil.com.br/legislacao/116689/decreto-23611-33>. Acessado em 23 de julho de 2011, as 20:23 horas.

DECRETO-Lei no 2.009, de 09 de fevereiro de 1940, dá nova organização aos núcleos coloniais. Disponível em: $\langle$ http://www6.senado.gov.br/sicon/\#> acessado em 22 de julho de 2011, as 22:19 horas.

DECRETO-Lei no 3.059, de 14 de fevereiro de 1941, dispõe sobre a criação de Colônias Agrícolas Nacionais. Disponível em:<www.jusbrasil.com.br/legislacao/navegue/1943/Decretos>. Acessado em 23 de julho de 2011, as 16:09 horas.

DECRETO-Lei $\mathrm{n}^{\circ} 7.038$, de 10 de novembro de 1944, dispõe sobre a sindicalização rural. Disponível em:< $\underline{w w w . l e x m l . g o v . b r / . . / u r n: l e x: b r: f e d e r a l: d e c r e t o . l e i: 1944-1 \ldots . . . ~ A c e s s a d o ~ e m ~} 22$ de julho de 2011, as 19:00 horas.

DECRETO-Lei $\mathrm{n}^{\circ} 7449$ de 09 de abril de 1945, dispõe sobre a organização da vida rural. Disonível em: $\langle$ www.jusbrasil.com.br/legislacao/.../decreto-lei-7449-45>. Acessado em 22 de julho de 2011, as 19:20 horas.

DECRETO-Lei ${ }^{\circ}$ 8.127, de 24 de outubro de 1945, dispõe sobre a organização da vida rural. Disponível em: $\langle$ www.jusbrasil.com.br/legislacao/.../decreto-lei-8127-45 $>$. Acessado em 22 de julho de 2011, as 19:16 horas.

LEI $\mathrm{n}^{\circ} 4.214$, de 2 de março de 1963, dispõe sobre o "Estatuto do Trabalhador Rural". Disponível em:<www010.dataprev.gov.br/sislex/paginas/42/1963/4214.htm >. Acessado em 23 de julho de 2011, as 15:00 horas.

LEI $\mathrm{n}^{\circ}$ 4.504, de 30 de novembro de 1964, dispõe sobre o Estatuto da Terra. Disponível em:<www.planalto.gov.br/ccivil_03/leis/L4504.htm>. Acessado em 23 de julho de 2011, as 18:20 horas.

LEI $\mathrm{n}^{\circ}$ 5.889, de 08 de junho de 1973, estatui normas reguladoras do trabalho rural. Disponível em:〈www.planalto.gov.br/ccivil_03/leis/15889.htm〉. Acessado em 23 de julho de 2011, as 22:34 horas.

LEI complementar $\mathrm{n}^{\circ}$ 11, de 25 de maio de 1971, institui o Programa de Assistência ao Trabalhador Rural. Disponível em:<www.planalto.gov.br/ccivil 03/leis/LCP/Lcp11.htm>. Acessado em 23 de julho de 2011, as 19:03 horas.

Bibliografia:

AVRITZER, Leonardo. Terra e cidadania no Brasil. In: STARLING, Heloisa Maria Murgel et. al. (org.). Utopias agrárias. Belo Horizonte: editora UFMG, 2008.

BOCCARA, Guillaume. Mundos nuevos en las fronteras del Nuevo Mundo. In: Nuevo Mundo Mundos Nuevos, Debates, 2005, [En línea], Puesto en línea el 08 febrero 2005. URL: http://nuevomundo.revues.org/426. Consultado el 02 agosto 2010.

BORGES, Barsanulfo G. A expansão da fronteira agrícola em Goiás. História Revista - Revista da Faculdade de História e do Programa de Pós-Graduação em História da Universidade Federal de Goiás. Vol. 1, nº 2, p 37-55, jul./dez. 1996. disponível em: http://www.revistas.ufg.br/index.php/historia/article/view/. Acessado em 22 de maio de 2011 às 10:11 horas.

BORGES, Maria Elisa Linhares. A recriação de uma fronteira: a luta pela terra no leste de Minas Gerais. In: Revista de Estudos Políticos, separata do número 73 (p173-201). Belo Horizonte, 1991.

Representações do universo rural e luta pela reforma agrária no Leste de Minas Gerais. Rev. Bras. Hist. [online]. 2004, vol.24, n.47, p. 303-326. Disponível em: http://www.scielo.br/scielo.php. Acessado em 17 de maio de 2011 às 09:40 horas.

Reforma Agrária e identidade camponesa. In: REIS, Daniel Aarão, RIDENTI, Marcelo e SÁ MOTTA, Rodrigo Patto. (orgs). O golpe e a ditadura militar: quarenta anos depois (1964-2004). . Bauru, SP: Edusc, 2004 (81-100). 
BRUNO, Regina. O Estatuto da Terra: entre a conciliação e o confronto. In: Estudos Sociedade e Agricultura, 1995. Disponível em:<bibliotecavirtual.clacso.org.ar/ar/libros/brasil/.../regina5.ht...>. Acessado em 14 de julho de 2011 às 13:15 horas.

CAMBRAIA, Ricardo de Bastos e MENDES, Fábio Farias. A colonização dos sertões do leste de Mineiro: políticas de ocupação territorial num regime escravista (1780-1836). Revista do Departamento de História, $\mathrm{n}^{\circ}$ 6, julho de 1988, (137-150).

CANDIDO, Antônio. Os parceiros do Rio Bonito: estudo sobre o caipira paulista e a transformação dos seus

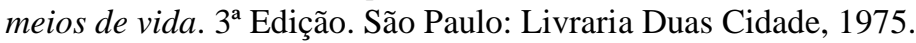

CARVAlHO, José Murilo de. Cidadania no Brasil: o longo caminho. $11^{\mathrm{a}}$ ed. Rio de Janeiro: Civilização Brasileira, 2008.

CASTALDI, Carlo. A aparição do demônio do Catulé. In: Tempo Social, revista de sociologia da USP, v. 20, n. 1, 2008, p 343-344. Disponível em: http://www.scielo.br/pdf/ts/v20n1/a16v20n1.pdf. Acessado em 22 de maio de 2011, às 11:20 horas.

COSTA, Fernanda Laura. Capitalismo autoritário e modernização. In: ANPUH-ES. ANAIS ELETRÔNICOS DO IV ENCONTRO DA ANPUH-ES. História, representações e narrativas. Vitória, 2003. ISBN 85-903587-4-7. Disponível em http://www.angelfire.com/planet/anpuhes/anais4.htm. Acessado em 22 de maio de 2011 às 10:22 horas.

CUNHA JÚNIOR, Dirley da. Terras Devolutas nas Constituições Republicanas. Disponível In: <www.jfse.jus.br/obras\%20mag/artigoterrasdevdirley.htm. Acessado em 13 de julho de 2011 às 14:13 horas.

ESPINDOLA, Haruf Salmen. A história de uma formação socio-econômica urbana: Governador Valadares. Varia Historia, Belo Horizonte, nº 19, novembro de 1998, (148-163).

FARIA, Camila Salles de e OLIVEIRA, Ariovaldo Umbelino. O processo de constituição da propriedade privada da terra no brasil. Disponível In:<egal2009.easyplanners.info/.../6193_OLIVEIRA_Ariovaldo_Umbelino.doc〉. Acessado em:13 de julho de 2011 às 22:30 horas.

FERREIRA, Andrey Cordeiro. Políticas para fronteira, História e Identidade: a luta simbólica nos processos de demarcação de terras indígenas Terena. In: Revista Mana, vol. 15, no 2 Rio de Janeiro, oct. 2009. Disponível em: <http://www.scielo.br/scielo.phd?pid=S0104-93132009>. Acessado em 10 de agosto de 2010 às 08:37 horas.

FERREIRA, Nilda Teves. Cidadania - uma questão para a educação. Rio de Janeiro: Ed. Nova Fronteira, 1993.

GENOVEZ, Patrícia Falco e VILARINO, Maria Terezinha Bretas. Entre práticas sanitárias e saberes tradicionais: a territorialização do saneamento no Médio Rio Doce. In: ABREU, Jean Luiz Neves e ESPINDOLA, Haruf Salmen (Org). Território, Sociedade e Modernização: Abordagens Interdisciplinares. Governador Valadares: Ed. Univale, 2010.

GOMES, Ângela Maria de Castro [et al.]. Brasil Republicano: sociedade e política (1930-1964). $9^{\circ} \mathrm{ed}$. Rio de Janeiro: Bertrand Brasil, 2007.

HAGUETTE, Tereza Maria Frota. O cidadão e o estado. Fortaleza: Editora UFCE, 1994.

JACKSON, Luiz Carlos. A tradição esquecida: os parceiros do Rio Bonito e a sociologia de Antônio Candido. Belo Horizonte: Ed. UFMG; São Paulo: FAPESP, 2002.

KARAWEJCZYK, Mônica. Mulheres Lutando por sua cidadania políticia - um estudo de caso: Diva Nolf Nazário e sua tentativa de alistamento 1922. In: X Encontro Estadual de História. O Brasil no Sul: Cruzando frotneira entre o Regional e o Nacional. Santa Maria: Universidade Federal de Santa Maria e Centro Universitário $\quad$ Franciscano, 2010. Disponível em: $<$ http://www.eeh2010.anpuhrs.org.br/resources/anais/9/1279290254_ARQUIVO_MK-Mulhereslutandoporsuacidadaniapolitica.pdf >.

Acessado em: 11 de julho de 2011 às 11:00 horas.

Em Tempo de Histórias - Publicação do Programa de Pós-Graduação em História da

Universidade de Brasília PPG-HIS, no. 19, Brasília, ago/dez. 2011. ISSN 1517-1108 
MARTINS, J. S. Expropriação e Violência (A questão política no campo). São Paulo, Huctec, 1980.

MARTINS, José de Souza. Os camponeses e a política no Brasil. Petrópolis/Rio de Janeiro: Vozes, 1981.

MEDEIROS, Leonilde Sérvolo de. História dos movimentos sociais no campo. Rio Janeiro: FASE, 1988. . Os trabalhadores do Campo e desencontros nas lutas por direitos. Disponível In: $\langle$ http://www.ufrrj.br/cpda/main/bib_lp.php?tp=M $>, 2002$. Acessado em: 12 de julho de 2011, às 22:00 horas. . Movimentos sociais no campo, lutas por direito e reforma agrária na segunda metade do século XX. In: CARTER, Miguel (org.). Combatendo a desigualdade social - O MST e a reforma agrária no Brasil. São Paulo: Editora UNESP, 2010, p 113-136.

MENEZES, Albene Miriam. Utopia, imigração e a colônia alemã de Una, Bahia no contexto histórico. In: Dossiê - Brasil/Alemanha: Imigração, Cidadania e Cooperação. Texto de História: Revista do Programa de PósGraduação em História da UnB. Brasília:UnB, vol. 16, nº 2, 2008.

NEVES, Lucília de Almeida. Cidadania: Dilemas e perspectivas na República Brasileira. Revista Tempo, Rio de Janeiro, vol. 4, 1997, p 80-102.

PEREIRA, Carlos Olavo da Cunha. Nas terras do rio sem dono. Rio de Janeiro: Editora Coderci/Pasquim, vol. 4, 1988.

PEREIRA, José Flávio e PEREIRA, Lupércio Antônio. Instituições jurídicas, propriedade fundiária e desenvolvimento econômico no pensamento de José da Silva Lisboa (1829). In: Revista História, vol.25, no.2,

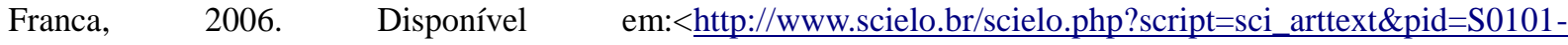
90742006000200010>. Acessado em: 15/07/2011 às 12:31 horas.

SANTOS, Wanderley Guilherme. Cidadania e justiça: a política social na ordem política brasileira. Rio de janeiro: Campus, 1997.

SILVA, Lígia Osório. Terras e Latifúndio - Efeitos da Lei de 1850. Ed. Unicamp, Campinas-SP, 1996.

SILVA, Maria do Socorro. A História das nossas raízes: Intinerário das Lutas dos Trabalhadores (as) rurais no Brasil e 0 surgimento do Sindicalismo Rural. In:<www.lecampo.com.br/.../Texto_A_HISTORIA_DAS_NOSSAS_RAÍZES >, 2006. Acessado em: 14 de julho de 2011 às 09:20 horas.

STEIN, Leila de Menezes. Trabalhismo, círculos operários e política: a construção do Sindicato de Trabalhadores Agrícolas no Brasil (1954-1964). São Paulo: Ed Annablume, 2008.

WELCH, Clifford Andrew. Movimento sindical dos trabalhadores rurais no pré-1964. Grand Valley State University Nera, Unesp - Presidente Prudente, 2009.

VELHO, Otávio Guilherme. Capitalismo autoritário e campesinato: Um estudo comparativo a partir da fronteira em movimento. São Paulo: Corpo e Alma do Brasil, 1979. 